\title{
The Assessment of Economic Efficiency of Regulatory Impact on the Crowd Financing Market
}

\author{
U.V. Kuvaeva, M.V. Chudinovskikh, N.L. Boronenkova, and A. N. Sergienko \\ Ural State University of Economics, 620144 Ekaterinburg, Russia
}

\begin{abstract}
In the last few years, conditions have been created in the world economy that contribute to the active crowdfunding market development, through which the so-called «alternative financing» is implemented. The paper describes the transformation of crowdfunding model types, emphasizes the importance of regulatory impact on the specified market. The general procedure for regulatory impact assessments (RIA), developed and recommended by the OECD based on scientific approaches, is considered. The specificity of the approach to RIA in Russia was studied and the conclusion was made about the need to apply RIA to the crowdfunding market, taking into account the improvement of approaches to assessing the costs and benefits of regulation.
\end{abstract}

\section{Introduction}

The initial stage in the formation of approaches to the description of instruments and models of alternative financing should be considered as 2014 year, when the first concept paper of the International Organization of Securities Commissions (IOSCO) on this issue was published. Crowdfunding, as defined by IOSCO in 2014, had four subcategories:

- crowdfunding donations;

- crowdfunding rewards;

- peer-to-peer (P2P) lending;

- equity crowdfunding.

The further transformation of crowdfunding subcategories was predetermined by the rapid development of the alternative financing market and the massive use of crowdfunding technologies, first in European countries and then around the world. In this regard, the world landscape has already been represented by 2020 with fifteen model types of crowdfunding operating in different regions of the world, among which stand out P2P Consumer Lending, Invoice Trading, P2P Business Lending, Real Estate Crowdfunding, Equity-based Crowdfunding, Reward-based Crowdfunding, Balance Sheet Business Lending, Balance Sheet Consumer Lending, Balance Sheet Property Lending, Community Shares, Debt-based Securities, P2 P Property Lending, Donation-based Crowdfunding, Mini Bonds, Revenue Sharing [1].

Such a significant transformation of crowdfunding model types in the global landscape makes us increasingly focus on two major issues: 
1. Necessity and sufficiency of the regulatory impact on the crowd financing market in a broad sense.

2. Search and application of tools (methods) for assessing the economic efficiency of such a regulatory impact.

\section{Methods}

The active development of crowdfunding entails the need to search for tools to assess the economic efficiency of the regulatory impact on the specified market. The aim of this research is to study modern RIA methods used in world practice, assess the shortcomings of RIA in Russia and draw conclusions in terms of assessing the regulatory impact on the crowdfunding market.

The research included several stages:

- analysis of statistical data;

- study of the developed approaches to conducting RIA proposed by the OECD;

- description of scientific schools within which researchers are assessing the economic efficiency of regulatory impact;

- analysis of domestic regulatory legal acts describing the procedure and methodology for conducting RIA.

To undertake the study, a formal-logical method, comparison, analysis, synthesis, comparison and generalization were used.

\section{Results and Discussion}

One of the first attempts to legislatively regulate relations in the field of crowdfunding was carried out by the United States of America, which in 2012 adopted the Jumpstart our Business Startups Act "(JOBS Act). In 2015, at the European Union level, there were also attempts to regulate this area, and by May 2016, seven out of twenty-eight members states of the European Union had introduced national legislation that related to Equity-based Crowdfunding. The rules introduced by the European states related mainly to the of platforms licensing, limits on the amount of of funds collection, restrictions on the invested amounts for unqualified investors [2]. At the same time, the EU member states did not pay special attention to the regulation of Donation-based Crowdfunding and this crowdfunding model type remained in the sphere of regulation of the current legislation.

The European Commission and the European Parliament have shown a constant interest in crowdfunding [3], while noting the need to maintain a regular dialogue with European supervisory authorities, EU member states and the crowdfunding sector. In March 2018, as part of the Fintech Action Plan, the European Commission submitted a proposal for uniform regulation of crowdfunding service providers, which allowed platforms to apply for an EU passport based on a single set of rules. In this case, the regulatory requirements again apply only to crowdfunding model types and entail financial returns for investors (investment crowdfunding).

On June 24, 2019, the European Parliament and Council Regulation Proposals on European Crowdfunding Service Providers (ESP) for Business and Amendments to the Regulation (EU) were published. The paper notes the importance of helping cross-border crowdfunding platforms remove barriers; introduction of adapted rules for crowdfunding companies in the European Union, depending on the model type of crowdfunding, etc. On July 12, 2019, the European Securities and Markets Authority posted a Status Report on the licensing regimes for FinTech companies in the EU. 
In the ASEAN countries (Brunei, Cambodia, Indonesia, Laos, Malaysia, Myanmar, the Philippines, Singapore, Thailand and Vietnam), there is also an active discussion about the need for a regulatory impact on the crowdfunding market, while several regulation models of relations are currently noted in this region in the field of crowdfunding:

- model 1: unregulated but not prohibited mode;

- model 2: regulated mode: regulated under bespoke regulation individual regulation;

- model 3: regulated mode: regulated under existing legislation [4].

Thus, stating that in developed and developing countries the regulatory process in the crowdfunding market is moving forward, we note one more moment that is most important in our opinion. The specific risks of relations in the crowdfunding market, the genesis of this phenomenon in general, as an alternative to traditional banks and other financial institutions in the context of disintermediation of financial markets, put on the agenda the most important issue related to the need to find and apply tools (methods) for assessing the economic efficiency of regulatory impact on crowdfunding market.

The 2008 global financial crisis exposed serious problems in government and regulatory practice around the world and in this regard, in 2012 the OECD developed the first Recommendation on Regulatory Policy and Governance. The concept of regulatory policy combines a wide range of government regulation forms of entrepreneurial activity, including the creation of various conditions for access to the market, the establishment of mandatory requirements for products and processes, control and supervisory procedures, prohibitions, restrictions, preferences, etc. The Organization for Economic Co-operation and Development considers regulatory policy, along with monetary and budgetary policy, as one of the main drivers of economic growth, which, if adjusted effectively, can give up to $1,5-2,5 \%$ of GDP growth per year, as well as ensure an increase in the level of employment, labor productivity, entrepreneurial and innovative activity, a significant inflow of foreign investment [5].

The most common and well-known regulatory policy instrument is the regulatory impact assessment (RIA), which is understood as «... the process of defining regulatory problems and objectives, choosing alternatives to achieve these goals, in order to avoid unnecessary and thoughtless regulation, and using scientific and verifiable techniques applied to all the available information, as well as taking into account the different opinions obtained in the course of consultations, cost-benefit analysis of the selected alternatives ...» [6]. On the website of the State Duma of the Russian Federation we find the following definition: «regulatory impact assessment is a way to assess the positive and negative effects of existing or introduced regulation. It can be applied both in anticipation of changes in regulation (Latin - ex-ante, assessment of the expected impact) or after a new regulation has come into force (Latin - ex-post, assessment of real impact)».

The need on the part of governments «to introduce regular assessments of the effectiveness of laws, standards and regulatory systems, taking into account, among other things, their implications for affected parties and their reactions» is noted in a number of OECD policy documents on regulatory policy and governance. Moreover, OECD guidelines on RIA on a regular basis suggest that efficiency / reduction of overhead costs should be considered as the main motivation for RIA introduction, so that the benefits are greater than the costs, provided that impacts can be monetized safely and accurately. In this way, the main emphasis in conducting RIA should be primarily on the analysis of the effectiveness of the regulatory impact of legal norms on the economy.

It is important to note that the scientific basis of RIA, as the core of regulatory policy and management, is formed by various schools, including the Chicago approach to law and economics, public choice theory, the institutional school of law and economics, as well as neoinstitutionalism. The Chicago Approach, pioneered by eminent scholars such as Ronald 
G. Coase, Guido Calabresi, Henry Manne, Garry Bakker and Richard A. Posner, emphasizes that legal decision-making and legal assessment should be based on costeffectiveness. This category, in turn, can be described by three concepts: efficiency in exchange, efficiency in production, and the Kaldor-Hicks efficiency criterion. A distinctive feature of the "Chicago approach" is that its representatives use the Kaldor-Hicks efficiency criterion, or the wealth maximization criterion, the essence of which is as follows: «a change in legislation increases efficiency if the gains to those who won outweigh the losses of the losers. In this case, the winners could (hypothetically) compensate the losers for their losses and still win» [7]. For Kaldor-Hicks effectiveness, the payment of such compensation is not a necessary condition for the decision to be considered cost-effective. So, for instance, if the introduction of import customs duties allows local producers to earn more than importers lose, according to the Kaldor-Hicks criterion, we can talk about an increase in economic efficiency [8].

As part of the use of the Kaldor-Hicks performance criterion to assess the regulatory impact, the OECD in 2014 attempted to systematize the costs (losses) and profits of regulation $[9,10]$. Regulatory costs in the interpretation of OECD policy documents are called «regulatory costs» and include all costs associated with the adoption of a regulatory requirement, or direct or indirect in nature and incurred either by business, consumers, government or its relevant authorities as well as other groups. The taxonomy of normative costs given in [9] is described as follows:

1. Compliance Costs. These include:

A) administrative burden - costs associated with the fulfillment of information obligations by regulated entities arising from state regulation. Information obligations can be defined as regulatory obligations to provide information and data to the public sector or to third parties.

Б) Substantive compliance costs. These include the additional costs for the target group associated with compliance with a given regulation, in addition to administrative costs. They include only direct costs incurred by those who are subject to compliance obligations by the regulation. Major compliance costs include the following broad categories: implementation costs, direct labor costs, overhead costs, equipment costs, material costs, and external service costs.

B) Administration \& enforcement costs. This refers to the costs incurred by the government in relation to administration and compliance.

2. Financial costs. The financial value of regulations is the cost of capital allocated to meet compliance obligations. In other words, these are the aggregate investment obligations, the fulfillment of which is required from the company as a result of the introduction of a particular regulatory initiative (for example, equipment purchased, etc.).

3. Indirect costs are the so-called «second level» costs and these costs are secondary to the main goal of regulation. Dynamic costs can be included in this category, that is, costs caused by negative changes in market conditions over time (for example, an increase in emissions charges causes an increase in the prices of goods, the production of which requires emissions, respectively, the demand for these goods decreases, causing a loss in profit).

4. Opportunity costs is a cost that arises from the need to divert resources into compliance with regulatory requirements and to abandon their more preferred (i.e. more productive) use.

5. Macroeconomic costs. In this case, we are talking about the cost impact on key macroeconomic variables such as GDP and employment, caused by regulatory requirements. It should be noted that only a few specific regulatory measures will have tangible macroeconomic costs. However, in some cases they can represent a very significant cost item. 
Regulatory benefits in [10] are presented as:

1. Direct regulatory benefits, including:

- improving the well-being of individuals, which in turn implies social and economic situation, as well as improved health, environmental and safety;

- increased efficiency, which includes in particular reduced costs, as well as the availability of information and an increased variety of products and services for consumers, and increased productivity (which often happens when the offer leads to increased access to information and communication technologies and their increased use).

2. Indirect regulatory benefits, including:

- $\quad$ side effects associated with compliance with legal regulations by third parties (socalled «indirect compliance benefits»);

- expanded macroeconomic benefits, including growth in GDP, productivity, employment, etc.; and

- other non-monetized benefits, for example, protection of basic rights, social community, international and national stability, etc.

3. The final impact of regulation, which in one way or another intersects with the ultimate goals of regulatory intervention (well-being of society as a whole, happiness and satisfaction with life, quality of the environment, etc.)

Thus, it should be stated that within the framework of the Kaldor-Hicks efficiency criterion in world practice, an attempt has been made to systematize all possible, from the point of view of the OECD, costs and benefits that all participants in the regulatory process bear.

To determine the size of the administrative costs of the regulatory process for business, the Standard Cost Model (SCM) was proposed in 2003, which has been recommended for use by the OECD in developed and developing countries since 2014. Within the framework of this model, the following regulatory costs for companies are distinguished:

1. Direct financial costs which is a result from a specific and direct obligation to transfer a specified amount of money to a government or competent authority. For example, the fee to apply for a license would represent the financial regulatory cost.

2. Compliance costs. In this case, we are talking about the costs of compliance with the regulation (meaning all costs associated with compliance with the rules, except for direct financial costs and long-term structural consequences).

3. Long term structural costs, including costs in the long run not covered by direct financial and regulatory compliance costs.

It is important to note that SCM, designed as a simple and reliable method for assessing the administrative costs of the regulatory process imposed by the government and individual departments, does not provide an answer whether the regulation is soundly introduced, it only estimates how much the regulation costs for business.

Taking SCM as a basis, the Ministry of Economic Development and Trade in 2015 approved the «Methodology for assessing the standard costs of entrepreneurial subjects and other economic activity arising in connection with the fulfillment of regulatory requirements» in which all costs of regulation described by SCM are divided into two groups of costs - informational and substantive. Information costs of regulation, in accordance with clause 3 of Section I of the specified methodology, include the costs of collecting, preparing and submitting information (documents, information) to public authorities in accordance with the requirements of the act, draft act, including the costs of maintaining the readiness to provide the necessary information at the request of the authorities or their authorized representatives. The substantive costs of regulation include the costs of implementing the provisions of the act, the draft act, not related to the implementation of information requirements. Such costs are divided into one-time, incurred 
at the time the requirements of the act, draft act, and long-term, regularly carried out throughout the entire period of the claim.

As for the benefits of the regulatory impact, a fragmentary mention of them is contained in the «Form of the summary report on the conduct of the regulatory impact assessment, the form of the conclusion on the assessment of the regulatory impact, the methodology for assessing the regulatory impact», approved by order of the Ministry of Economic Development of Russia dated May 27, 2013 N 290, where it is very brief mentions the need to describe in the report on the conduct of RIA «the advantages and (or) other benefits of small and medium-sized businesses (which can be expressed, for example, in the provision of tax incentives, subsidies or other benefits and (or) advantages)».

In this way, we observe, on the one hand, that the RIA procedure in Russia focuses to the greatest extent on detailing the costs of business for compliance with regulatory legislation without studying and analyzing the costs of all entities that may be influenced in one way or another by the regulatory initiative. On the other hand, it should be noted that in the domestic RIA methodology, there are practically no attempts to describe and quantify the benefits of regulatory impact not only for all participants, but also for business, which contradicts the OECD recommendations.

\section{Conclusions}

As for assessing the economic efficiency of the regulatory impact on the crowdfunding market, the following should be noted. Both the International Organization of Securities Commissions and the European Securities and Markets Authority have repeatedly noted the great potential for accelerating economic growth through the further development of the crowd financing market. This circumstance forces various countries to design regulatory processes in this area in such a way that, on the one hand, they protect the interests of investors in this market, and on the other hand, contribute to the development of the crowdfunding phenomenon. For this reason, the issues of economic efficiency of the regulatory impact on this market in the world, and especially in developed countries, are given special attention, in contrast to Russia, where advanced practices and techniques are used in a very peculiar way or are not used at all.

A striking example of this is the law «On Attracting Investments Using Investment Platforms and on Amending Certain Legislative Acts of the Russian Federation» dated 02.08.2019 N 259-FZ, which came into force on 01.01.2020, regulating legal relations in the crowdfunding market. This document introduces a new instrument into civil circulation - «utilitarian digital law». In paragraph 3 of Art. 8 of this law, the legislator formulates a direct definition of this new term: «Utilitarian digital rights are recognized as rights if they originally arose as digital rights on the basis of an agreement on the acquisition of utilitarian digital rights concluded using an investment platform, in accordance with the rules of Article 13 of Federal Law No. 259-FZ». In our opinion, such a legal formulation can cause nothing except emotions. It seems that, provided that a high-quality RIA procedure is applied at the stage of consideration and approval of this draft law, such a definition could hardly appear in the final version of the law. It is undeniable that an adequate regulatory policy in the digital space of the financial market, and in particular in such a segment as crowdfunding, contributes to the timely and effective implementation of new digital entities in the economic and legal turnover, which will largely determine the level of development of any economy. 


\section{References}

1. The Global Alternative Finance Market Benchmarking Report, Trends, Opportunities and Challenges for Lending, Equity, and Non-Investment Alternative Finance Models, https://www.jbs.cam.ac.uk/

2. G. Gabison, Understanding Crowdfunding and its Regulation. How can Crowdfunding help ICT Innovation? (2015) http://publications.jrc.ec.europa.eu/

3. A. Delivorias, Crowdfunding in Europe: Introduction and State of Play, EPRS Briefings (2017) http://www.europarl.europa.eu/

4. U. V. Kuvaeva, M.V. Chudinovskikh, Banking, 5, 57 (2020)

5. A.E. Golodovnikova, A.A. Efremov, D.V. Sobol, D.B. Tsygankov, M.S. Shklyaruk, Regulatory policy in Russia: main trends and architecture of the future, https://cyberleninka.ru/

6. M.V. Ivanova, Models and methods of assessing the regulatory impact in the state administration of Russia and foreign countries, 95 (2018)

7. N. Mercuro, S.G. Medema, Economics and the Law: From Posner to Post-Modernism and Beyond, 2 (2006)

8. A.G. Karapetov, Economic analysis of law, 528 (2016)

9. Regulatory Compliance Costs Assessment Guidance, OECD Publishing (2014) https://www.oecd.org/

10. GSR14 discussion paper Using Regulatory Impact Analysis to Improve Decision Making in the ICT Sector, https://www.itu.int/ 